\title{
Reinforcement of leverholding by avoidance of shock
}

\author{
HANK DAVIS and JO-ANN BURTON \\ University of Guelph, Guelph, Ontario, Canada N1G 2W1
}

\begin{abstract}
The properties of leverholding occurring under a procedure in which subjects were required to remain in continuous contact with the lever to avoid shock were examined and compared to nonreinforced leverholding which occurred under a traditional shock escape procedure. Long-Evans rats, exposed to either the avoidance or escape procedure, were run under both a 15- and 60-g response force criterion. Subjects in the avoidance condition spent an average of $97 \%$ of session time in contact with the lever, although these data were affected by the number of previous sessions and the response force criterion. Despite the appearance of some "warm-up" effect, many leverholding avoidance sessions were virtually shockfree. The mean force of leverholding during avoidance exceeded values obtained under the escape condition, as well as substantially exceeding the force criterion under which the behavior occurred.
\end{abstract}

In 1953, Sidman introduced a free-operant procedure for training subjects to avoid shock. In the past 2 decades, this procedure has enjoyed widespread popularity and has been investigated parametrically using a variety of responses and a number of different species (see review by Sidman, 1966).

Throughout all of this research, however, it appears that the free-operant avoidance procedure has been applied primarily to "discrete" responses, i.e., relatively brief contacts with the manipulandum. A procedure introduced earlier by Hefferline (1950) suggests that continuous responding (i.e., "leverholding") may also be reinforced by avoidance of an aversive stimulus. Hefferline's procedure, which has been largely ignored since its introduction, dealt with avoidance of light by rats. The present experiment investigates free-operant avoidance performance by rats when leverholding is reinforced by avoidance of shock.

Leverholding, per se, has generated considerable attention, although most often as a behavioral side effect, rather than as an explicitly reinforced response. To date, most interest in leverholding has taken one of two directions. The first focuses upon its properties, such as force and duration (e.g., Davis \& Burton, 1974); the second explores the function of leverholding, either within the experimental situation (e.g., Campbell, 1962) or in relation to the natural history of the subject (e.g., Bolles, 1970).

A considerable number of investigations of leverpress escape and avoidance behavior have reported the persistence of leverholding, despite the fact that this behavior was not explicitly reinforced (Hurwitz, 1967; Keehn \& Walsh, 1970). Rather than attempt to disrupt or eliminate leverholding (c.f. Feldman \& Bremner, 1963;

This research was supported in part by a Research Advisory Board grant from the University of Guelph to the first author, and by Grant A8264 from the National Research Council of Canada to Harry M. B. Hurwitz, to whom the authors are indebted. The technical help of Daniel J. Whitley and John W. Porter was much appreciated. Reprints may be obtained from Hank Davis, Department of Psychology, University of Guelph, Guelph, Ontario, Canada N1G 2W1.
Forgione, 1970), this class of behavior has been explicitly reinforced in the present experiment by making avoidance of shock contingent upon it. The properties of leverholding resulting from direct reinforcement were then compared with leverholding which emerged "fortuitously" under a traditional leverpress shock escape procedure.

\section{METHOD}

\section{Subjects}

Twelve experimentally naive male Long-Evans rats served as subjects. They were approximately 180 days old with a mean weight of $460.5 \mathrm{~g}$ at the beginning of the experiment. Subjects were individually housed, with food and water freely available in their home cages.

\section{Apparatus}

All subjects were tested in a 30.5 by 20.3 by $19.0 \mathrm{~cm}$ (length by width by height) modified Lehigh Valley grid shock chamber. The floor consisted of 22 stainless steel grids, $.64 \mathrm{~cm}$ in diam, spaced $1.3 \mathrm{~cm}$ from center to center. Shock was delivered to the grid floor, walls, and lever of the chamber by means of a constant-current shock generator and scrambler (Campden Instrument Company, Model CI 521). A 1.3 by $5.1 \mathrm{~cm}$ response lever protruded $2.2 \mathrm{~cm}$ from the front cage wall, $5.1 \mathrm{~cm}$ above the grid floor.

In addition to traditional measurement of response frequency and latency, the amount of downward force the subject exerted on the lever was expressed as a pen deflection on a Beckman physiograph (Type RS). The apparatus for recording response force has been described in detail elsewhere (Davis \& Burton, 1974). Prior to each experimental session, a Schmitt trigger was adjusted to allow the appropriate response force criterion $(15 \mathrm{~g}$ or $60 \mathrm{~g})$. Lever contact of insufficient force to operate the Schmitt trigger did not operate programming equipment involved in the escape or avoidance schedules; however, a continuous record was obtained on the physiograph of all lever contact, regardless of force.

\section{Procedure}

Subjects were randomly assigned to one of two conditions: a conventional escape schedule or the leverholding avoidance procedure. Each subject was exposed to two different response force criteria ( $15 \mathrm{~g}$ and $60 \mathrm{~g})$, and the order of presentation was varied within each condition.

Shock escape. Prior to the first experimental session, the six subjects assigned to the escape condition were trained by successive approximations to escape (terminate) shock with a lever- 


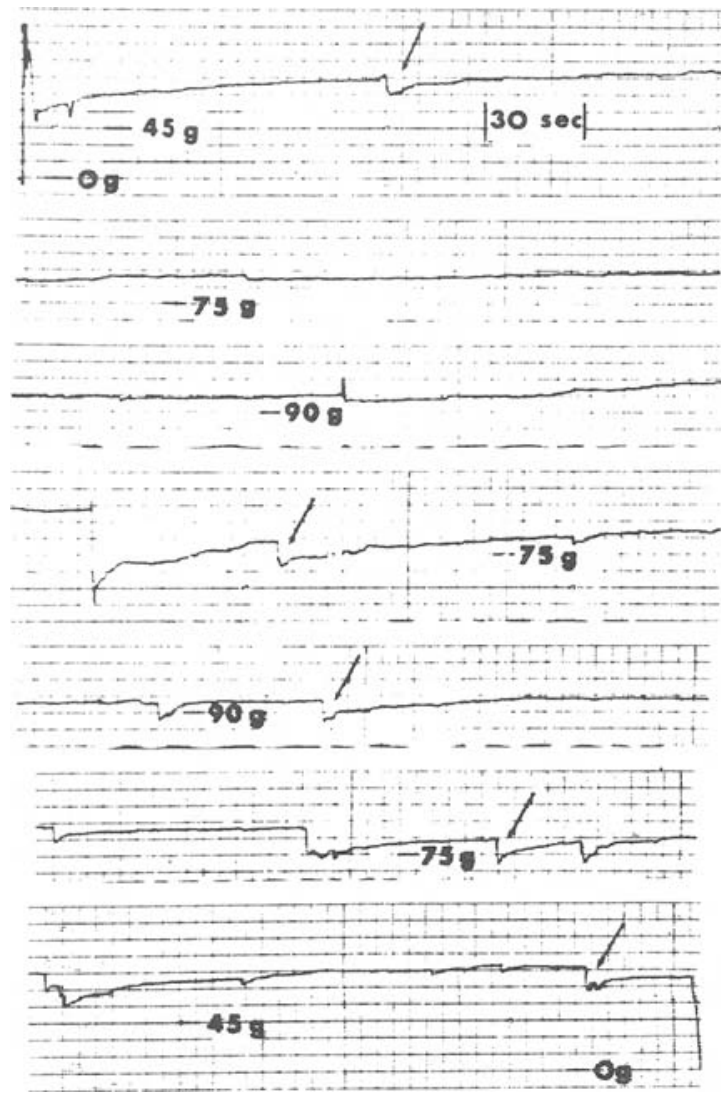

Figure 1. Continuous record of force of leverholding by Subject 4A60-15 during entire session in Phase II with 15-g response force criterion in effect. Shock delivery totaling $1.3 \mathrm{sec}$ occurred at start of session (upper record, left); balance of session was shockfree. Heavy horizontal rulings indicate $15-\mathrm{g}$ increments in force; vertical rulings signify 5 -sec periods. Note momentary dips of approximately $15 \mathrm{~g}$ in force of lever contact (at arrows) which occurred throughout session.

press response. Escape responses were recorded only after the lever had been released following the previous leverpress response. During experimental sessions, 50 shocks of .4-mA intensity were programmed to occur $30 \mathrm{sec}$ apart from shock offset to onset.

Leverholding avoidance of shock. Subjects assigned to the leverholding avoidance condition were pretrained by successive approximations to maintain the lever in a depressed position in order to continuously avoid shock. During experimental sessions, release of the lever to a force below criterion resulted in immediate onset of a .4-mA shock. Termination of shock and maintenance of the shock-free period required the subject to hold the lever with sufficient downward force to meet the response force criterion ( $15 \mathrm{~g}$ or $60 \mathrm{~g}$ ). Session length was equivalent to the approximate length of the escape session, i.e., 1,500 sec.

Response force criterion. During Phase I, half of the subjects from each condition were exposed to a 15-g response force criterion, and the remaining subjects were exposed to a $60 \mathrm{~g}$ criterion. In all cases, subjects were maintained at the same criterion used in pretraining. Phase I was continued for 12 daily sessions. During Phase II, which also consisted of 12 daily sessions, the response force criterion of subjects previously tested at $15 \mathrm{~g}$ was increased to $60 \mathrm{~g}$, and the criterion for subjects previously run at $60 \mathrm{~g}$ was reduced to $15 \mathrm{~g}$. Conditions were designated as $\mathrm{E}$ (escape) or A (avoidance), followed by a subscript indicating order of presentation of the response force criteria (e.g. E. 15-60. A60-15, etc.).

\section{RESULTS}

All subjects in the leverholding avoidance condition learned to remain in contact with the lever above the response force criterion in order to avoid shock. A comparison with subjects under the escape condition reveals that, regardless of force requirement, avoidance subjects reached a greater degree of "proficiency" than escape subjects, averaging $5.7 \mathrm{sec}$ of shock per session during the final half of Phase I, compared to $18.7 \mathrm{sec}$ for escape subjects $(p=.001$, Mann-Whitney $U$ test $)$.

\section{General Properties of Leverholding}

Figure 1 illustrates the general properties of leverholding when subjects were required to remain in contact with the lever continuously in order to avoid shock. No sessions were shock free; subjects typically waited until shock onset at the start of the session before initiating lever contact. During the remainder of the session, shock onset resulted either from subjects gradually decreasing the amount of force exerted on the lever to a value below criterion, or, more frequently, from subjects "suddenly" releasing the lever while holding at a value in excess of the response force criterion. As sessions progressed, the amount of shock decreased until, in many instances, total shock duration under the avoidance procedure was as brief as a latency recorded on a single trial under the escape condition
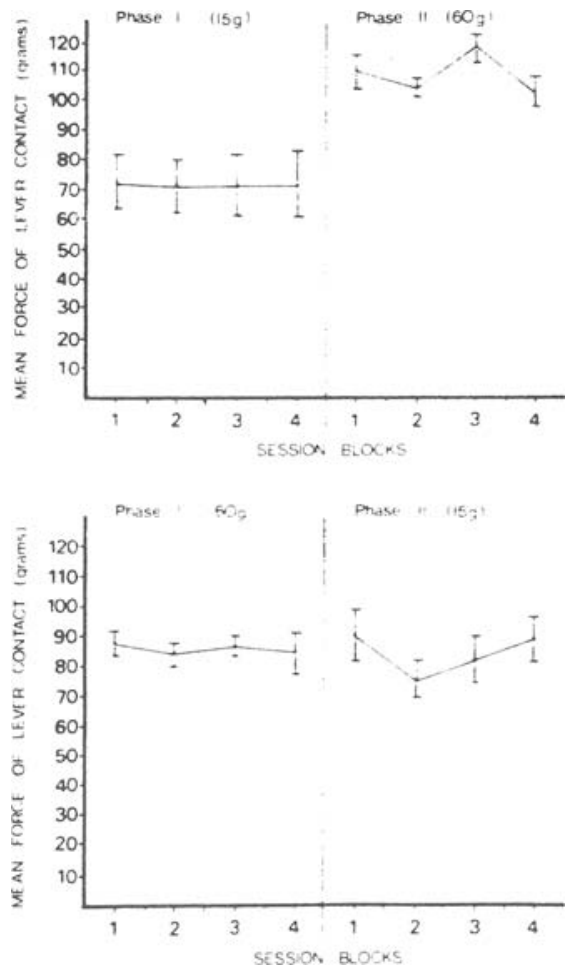

Figure 2. Mean force of leverholding recorded under avoidance procedure for subjects exposed to 15 - and $60 \mathrm{~g}$ response force criteria in Phases I and II (upper record), and 60- and 15-g criteria in Phases I and II (lower record). Data are plotted in blocks of three sessions. Vertical bars indicate standard error of the mean. 
(e.g., less than $.5 \mathrm{sec}$ ).

As indicated in Figure 1, it was common for avoidance subjects to show momentary drops in force, varying between 5 and $15 \mathrm{~g}$, during prolonged periods of stable leverholding. These changes in force, which were not confined to any particular porition of the session, usually occurred while lever contact was in excess of the criterion response force, and therefore did not result in shock onset. Their frequency of occurrence ranged between 0 and 15 times per session, with no systematic increase or decrease across sessions. As seen in Figure 1, the amount of force exerted by subjects often remained stable over long periods of time. One subject under the A60-15 condition maintained lever contact for $450 \mathrm{sec}$ without a single change in force in excess of $2 \mathrm{~g}$. No systematic tendence emerged for avoidance subjects to increase or decrease the force of contact within a session.

Under both the escape and avoidance conditions, shock onset consistently resulted in the subjects being thrown momentarily from the lever. Under the escape condition, once the subject returned to the lever and the force of contact reached a value in excess of the criterion, shock was terminated and remained off despite additional fluctuations in the force below criterion. Under the avoidance condition, however, shock was absent only as long as the force of leverholding remained above criterion. During early sessions, the instability of leverholding following shock typically resulted in cycles of relatively brief lever contacts and shocks. As sessions progressed and avoidance subjects learned to return to the lever and maintain the force above criterion, the duration of these cycles and, correspondingly, the number of very brief (e.g., .2-sec) shocks decreased.

\section{Mean Force of Leverholding}

Figure 2 indicates the mean force of leverholding in the A15-60 and A60-15 conditions. Although the decrease in criterion response force had relatively little effect on Group A60-15 subjects, the mean force of leverholding for Group A $15-60$ subjects increased from 72.0 to $109.3 \mathrm{~g}$ ( $\mathrm{p}=.125$, most extreme outcome, randomization test). This Phase II value was greater than that previously recorded under the same $(60-\mathrm{g})$ criterion for Group A60-15 subjects during Phase I $(p=.10$, randomization test).

Figure 3 illustrates the mean force of leverholding recorded under the escape condition. A comparison with Figure 2 reveals that the force of leverholding by avoidance subjects was consistently greater than that recorded by subjects under the escape procedure at both criterion force values regardless of phase (at $15 \mathrm{~g}$, mean $=56.7 \mathrm{vs}$. mean $=76.1$ for escape and avoidance conditions; $\mathrm{p}=.02$, Mann-Whitney $\mathrm{U}$ test; at $60 \mathrm{~g}$, mean $=58.0$ vs. mean $=99.9$ for escape and avoidance conditions; $\mathrm{p}=.01$, Mann-Whitney U test).

\section{Amount of Leverholding}

During the course of the experiment, leverholding by avoidance subjects was maintained for an average of
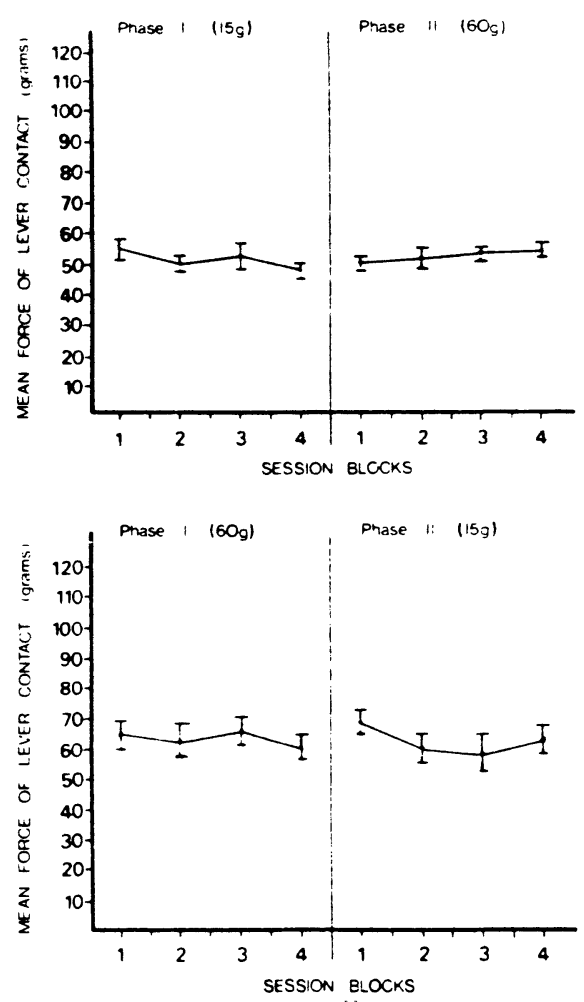

Figure 3. Mean force of leverholding recorded under escape procedure for subjects exposed to $15-$ and $60-g$ response force criteria in Phases I and II (upper record) and 60- and 15-g criteria in Phases I and II (lower record). Data are plotted in blocks of three sessions. Vertical bars indicate standard error of the mean.

$97.2 \%$ of session time in contrast to $68.0 \%$ for escape subjects. This difference was significant at both criterion response force values, regardless of phase (at $15 \mathrm{~g}$, mean $=63.1 \%$ vs. mean $=99.3 \%$ for escape and avoidance subjects, respectively; at $60 \mathrm{~g}$, mean $=70.8 \%$ vs. mean $=95.2 \%$ for escape and avoidance subjects; $\mathrm{p}=.001$ for both comparisons, Mann-Whitney U test).

\section{Total Shock Duration}

The increase to a $60 \mathrm{~g}$ response force criterion in both the $A_{15-60}$ and $E_{15}-60$ conditions resulted in an increase in the mean shock duration between the final block of Phase I sessions and the first session block of Phase II (mean $=16.5 \mathrm{sec}$ to mean $=27.1 \mathrm{sec}$ for $\mathrm{E}_{15-60 ; \mathrm{p}}=.125$, most extreme outcome, randomization test; mean $=2.5 \mathrm{sec}$ to mean $=105.9 \mathrm{sec}$ for A15-60 subjects, $p=.125$, most extreme outcome, randomization test). The decrease in response force criterion in Phase II, however, did not affect the amount of shock taken by either escape or avoidance subjects.

\section{DISCUSSION}

The addition of an explicit avoidance contingency for leverholding resulted in a number of differences from the leverholding recorded under the escape procedure. Because lever release resulted in immediate onset of shock under the avoidance procedure, it is reasonable that both the amount of leverholding and its sensitivity 
to the response force criterion were increased. That changing the response force criterion had little effect on the escape condition is not surprising, insofar as the force of leverholding was not differentially reinforced; i.e., unlike the avoidance condition, as long as the subject was in contact with the lever at the moment of shock onset, shock termination resulted from what has been described as a "reflexive lurch" from the lever (Bolles \& McGillis, 1968; Davis \& Burton, 1974).

The mean force of leverholding exerted by subjects in the avoidance condition consistently exceeded values obtained under the escape condition at both the 15- and 60 -g response force criteria. In addition, avoidance subjects typically exerted considerably greater force than that required by the criterion. Since leverholding was usually constant in force within a session, it would have been possible for subjects to maintain lever contact at somewhat lower force values without receiving more shock. This behavior, then, would seem to violate the principle of "least effort" (e.g., Tolman, 1932; Zipf, 1949). It is worth noting, however, that the occurrence of leverholding in escape conditioning was once similarly viewed as "inefficient;" (e.g., Dinsmoor \& Hughes, 1956), a view which was challenged by Campbell's (1962) demonstration that leverholding at the moment of shock onset was reliably correlated with shorter escape latencies. In addition, Bolles (1970), Bolles and McGillis (1968), and Davis and Burton (1975) have argued that intertrial leverholding may be a more fundamental aspect of escape behavior than the discrete leverpress escape response itself. In similar manner, the "unnecessarily" high force values exerted by avoidance subjects may be essential for successful performance under this condition. Perhaps subjects learn to maintain the force of holding well in excess of criterion, so that the regularly occurring "dips" in response force are less likely to result in the occurrence of shock.

Using a similar leverholding procedure, Hefferline (1950) suggested that sessions free of the aversive stimulus were not likely to occur, insofar as muscle strain associated with sustained leverholding might become more noxious than brief exposure to the aversive stimulus. Although this may have been the case when light was employed, our results suggest that muscle strain was more readily tolerated than brief exposure to shock. In the present experiment, many of the sessions were virtually free of shock, i.e., subjects responded within $.5 \mathrm{sec}$ of shock onset at the start of the session and did not release the lever until the session was terminated. The brief delay which occurred at the start of such sessions is more reasonable when understood in terms of a "warm-up" effect, which has been commonly reported in avoidance procedures in which discrete responding is reinforced (e.g., Powell, 1972). It is conceivable, however, that Hefferline's "muscular strain" explanation may account for those instances in the present study when subjects released the lever "suddenly" while holding at forces in excess of the criterion (e.g., Figure 1).
In contrast to many studies in which discrete avoidance responses are reinforced, the results of the present procedure suggest that shock avoidance by leverholding may be both readily learned and highly successful (cf. Meyer, Cho, \& Wesemann, 1960). This may be related to the fact that sustained lever contact is initially related to "freezing," a naturally occurring defense reaction in the rat (Bolles, 1970). In fact, it has been shown that discrete avoidance responding often follows a period of continuous leverholding (Davis, 1976; Hurwitz, 1967). A further reason for the rapid learning observed under the present procedure may be the immediate and continuous feedback to which the subject is exposed, in contrast to the paucity of stimulus change which typically accompanies Sidman avoidance performance.

\section{REFERENCES}

Bolles, R. C. Species-specific defense reactions and avoidance learning. Psychological Review, 1970, 77, 32-47.

Bolles, R. C., \& MCGillis, D. B. The non-operant nature of the barpress escape response. Psychonomic Science, 1908, 11, 261-262.

CAMPBELL, S. L. Lever holding and behavior sequences in shock-escape. Journal of Comparative and Physiological Psychology, 1962, 55, 1047-1053.

Davis, H. Response characteristics and control during leverpress escape. In H. Davis \& H. M. B. Hurwitz (Eds.), OperantPavlovian interactions. Lawrence Erlbaum, 1976, in press.

Davis, H. , \& Burton, J. The measurement of response force during a leverpress shock escape procedure in rats. Journal of the Experimental Analysis of Behavior, 1974, 22, 433-440.

Davis, H. \& Burton, J. An analysis of two extinction procedures for leverpress escape behavior. Bulletin of the Psychonomic Society, 1975, 5, 201-204.

Dinsmoor, J. A., \& Hughes, L. H. Training rats to press a bar to turn off shock. Journal of Comparative and Physiological Psychology, 1956, 49, 235-238.

Feldman, R. S., \& Bremner, F. J. A method for rapid conditioning of stable avoidance bar pressing behavior. Journal of the Experimental Analysis of Behavior, 1963, 6. 393-394.

Forglone, A. G. The elimination of interfering response patterns in lever-press avoidance situations. Journal of the Experimental Analysis of Behavior, 1970, 13, 51-56.

Hefferline, R. F. An experimental study of avoidance: Experiment 3: "Holding": The effects of differential reintorcement of components of the bar-pressing response. Genetic Psychology Monographs, 1950, 42, 263-283.

Hurwitz, H. M. B. Lever holding under free-operant avoidance. Journal of the Experimental Analysis of Behavior, 1967, 10, 551-554.

KEEHN, J. D., \& WALSH, M. Bar-holding with negative reinforcement as a function of press- and release-shock intervals. Learning and Motivation, 1970, 1, 36-43.

Meyer, D. R., Cho, C., \& Wesemann, A. F. On problems of conditioning discriminated leverpress avoidance responses. Psychological Review, 1960, 67, 224-228.

PowelL, R. W. Analysis of warm-up effects during avoidance in wild and domesticated rodents. Journul of Comparative and Physiological Psychology, 1972, 78, 311-316.

Sidman, M. Avoidance conditioning with brief shock and no exteroceptive warning signal. Science, 1953, 118, 157-158.

Sidman, M. Avoidance behavior. In W. K. Honig (Ed.), Operant behavior: Areas of research and application. New York: Appleton-Century-Crofts, 1966.

Tolman, E. C. Purposive behavior in animals and men. New York: Appleton-Century-Crofts, 1932. (Reprinted, University of California Press, 1949.)

ZIPF, G. K. Human behavior and the principle of least effort. New York: Hafner, 1949.

(Received for publication March 21, 1976.) 